Check for updates

Cite this: RSC Adv., 2017, 7, 21768

Received 24th January 2017

Accepted 3rd April 2017

DOI: 10.1039/c7ra01069a

rsc.li/rsc-advances

\section{Functionalized reduced graphene oxide (fRGO) for removal of fulvic acid contaminant}

\author{
Soumya Kanta Ray, (D) a Chanchal Majumder ${ }^{a}$ and Prosenjit Saha (D)*b
}

Iron-functionalized reduced graphene oxide (fRGO)-coated sand was used for the adsorption of natural organic matter, such as fulvic acid (FA), from synthetic water. A novel synthesis route was achieved to prepare an fRGO nanocomposite. FTIR, optical microscopy, scanning electron microscopy (SEM), transmission electron microscopy (TEM), and atomic force microscopy (AFM) were applied to investigate the morphologies and structures of fRGO. Removal kinetics (pseudo-second order) and adsorption isotherms (Langmuir and Freundlich) were investigated in terms of adsorbed total organic carbon (TOC) of FA to evaluate the removal rate and adsorption capacity. The effects of $\mathrm{pH}$ of the FA solution and the adsorbent dose $\left(0.5-2.5 \mathrm{mg} \mathrm{g}^{-1}\right)$ of fRGO were further evaluated for the determination of a possible removal mechanism. A comparative study of the adsorption efficiency of fRGO and powder activated carbon (PAC) was also carried out, and the results indicated a higher FA adsorption efficacy for fRGO. The $\pi-\pi$ interaction between the carbon atoms of FA and fRGO and electrostatic interaction between iron and functional radicals of FA were responsible for the removal.

\section{Introduction}

Fulvic acid (FA) represents a major component of natural organic matter (NOM); it adversely affects the vision and taste behavior and also imparts the formation of complexes with heavy metals and adsorbed organic contaminants. ${ }^{1,2}$ The presence of FA in natural water produces disinfection by-products (DBPs) during the disinfection process. Various types of DBPs such as trihalomethanes and halo acetic acids have been reported to be carcinogenic and mutagenic and cause other toxic effects in human beings. ${ }^{3-5}$ Therefore, removal of FA from water is very important for environmental and health considerations.

Several conventional methods such as coagulation/ flocculation, ion-exchange, membrane filtration, and adsorption $^{6}$ have been reported in the literature for the removal of FA. These conventional methods that utilize activated carbon and polymers have not been considered effective for the removal of FA contaminants since the size of FA particles is a few hundred nanometers or even less. ${ }^{7}$ However, in water treatment history, carbon is one of the most adaptable materials that is widely used for water purification. ${ }^{8,9}$ In the last three decades, nanoparticles have been increasingly applied in water purification as excellent adsorbents. ${ }^{9-11}$ Graphite oxide (GO), ${ }^{12}$ ornamented with different functional groups such as hydroxyl, epoxy, and carboxylic acid, can be further functionalized to prepare nanocomposites to be

${ }^{a}$ Department of Civil Engineering, Indian Institute of Science Engineering Science and Technology (IIEST), Shibpur, Howrah-711103, West Bengal, India

${ }^{b}$ M. N. Dastur School of Material Science and Engineering, Indian Institute of Science Engineering Science and Technology (IIEST), Shibpur, Howrah-711103, West Bengal, India.E-mail: senjitiitkgp@gmail.com coated on the layers of sand for specific contaminant removal. ${ }^{13-15}$ The functionalized or non-functionalized forms of graphene have been used as variants. ${ }^{16,17}$

Generally, a chemical oxidation method is used to functionalize graphene by $-\mathrm{OH}$ and $-\mathrm{COOH}$ groups. The functionalized GO system is highly dispersible in water compared to its primary counterpart. ${ }^{18}$ Iron complexes $\left(\mathrm{Fe}^{-} \mathrm{Fe}_{3} \mathrm{O}_{4}\right)$ are the most common functionalized metal-metal oxides applied with carbon-based nanocomposites for water treatment operations. ${ }^{19-21}$ Covalent or non-covalent bonds are created on the surfaces of graphene and GO to impart various functional groups..$^{22}$ The functionalization of carbonaceous nanomaterials has mainly contributed to the enhanced hydrophilicity of GO and graphene with increased dispersion to interact with chemical contaminants in aqueous media at the nanometer level. ${ }^{23}$ Anionic contaminants were removed by increasing the surface charge of different functional groups on nanomaterial surfaces. ${ }^{24-26}$ The removal mechanism has been proposed to be through $\pi-\pi$ interactions and cationic$\pi$ bonding. ${ }^{27}$ Generally, this removal is $\mathrm{pH}-$ dependent and follows the Langmuir adsorption model. Removal of mercury $\left(\mathrm{Hg}^{2+}\right)$ as a contaminant has been reported with the adsorption capacity of $980 \mathrm{mg} \mathrm{g}^{-1}$ through a synthesized, polypyrrolereduced graphene oxide (PPy-RGO) composite. ${ }^{28}$

Low-cost water purification filtration sand columns were developed using GO nanosheets, covalently modified with thiol groups on $\mathrm{sp}^{2}$ domains to remove heavy metals and organic dyes. ${ }^{29} \mathrm{~A}$ sand column coated with GO was reported to remove heavy metals and organic dyes at a 5-fold greater level compared to uncoated sand. Magnetite-reduced graphene (M-RGO) hybrids were used with RGO, with a particle size in the order 
of $10 \mathrm{~nm}$, to remove $\mathrm{As}(\mathrm{III})$ and $\mathrm{As}(\mathrm{v}) .{ }^{30}$ Above $99.9 \%$ arsenic was found to be removed within $1 \mathrm{ppb}$ limit from the synthetic water at the concentration of $1 \mathrm{mg} \mathrm{mL} \mathrm{m}^{-1}$. Batch mode adsorption studies were conducted for the removal of rhodamine-6G dye and chlorpyrifos pesticide by graphene prepared from an asphalt precursor followed by immobilization of graphene on sand..$^{31}$ An adsorption mechanism was established in a batch mode on the basis of time, particle size, and the adsorbent dose.

$\mathrm{Cu}$ (II) and $\mathrm{Pb}$ (II) were removed using a fixed-bed sand column by a graphene oxide (GO) layer under a steady flow of inlet air. ${ }^{32,33}$ However, the $\mathrm{Cu}$ (II) and $\mathrm{Pb}$ (II) removal efficiency decreased from $15.3 \%$ to $10.3 \%$ and from $26.7 \%$ to $19.0 \%$, respectively, when the injection flow rate was increased from 1 to $5 \mathrm{~mL} \mathrm{~min}^{-1}$. The increase in the amount of GO in the column was found to be efficient for the removal of actinides, such as Am(III), Th(Iv), $\mathrm{Pu}(\mathrm{Iv}), \mathrm{Np}(\mathrm{v}), \mathrm{U}(\mathrm{vI})$, and distinctive fission products, such as $\mathrm{Sr}(\mathrm{II})$, $\mathrm{Eu}(\mathrm{III})$ and $\mathrm{Tc}(\mathrm{VII})$, compared to that of traditional sorbents such as bentonite clays and activated carbon even at $\mathrm{pH}$ less than $2 .^{34}$ Methylene blue (MB) was found to be removed up to $99 \%$ by GO in an aqueous solution at the concentration of $250 \mathrm{mg} \mathrm{L}^{-1}$ with the adsorption capacity of $714 \mathrm{mg} \mathrm{g}^{-1} \cdot{ }^{35}$ A porous polysilicate acid/graphene composite was used to remove MB from the solution via chemical adsorption. ${ }^{36}$ A magnetic carbonate hydroxyapatite/graphene oxide (M-CHAP/GO) composite was used as a nice adsorbent to satisfactorily remove both lead $(\mathrm{Pb})$ and $\mathrm{MB}^{37}$ Aqueous graphene oxide (GO) removed $95 \%$ of the initial concentration of $\mathrm{MB}$ in a spontaneous manner. ${ }^{38} \mathrm{An}$ anionic azo dye was successfully removed by activated GO by decreasing the quantity of electronegative charges on the surface of GO. ${ }^{39}$ Heavy metals and dyes were efficiently removed through a manganese (Mn)-doped, iron nanocomposite. ${ }^{40}$

However, in reality, most of the abovementioned methods were found to be less applicable due to lack of acceptable effectiveness in the removal of FA from water. A robust and more practical process needs to be established for FA removal from natural water. In this study, RGO was prepared, functionalized with an iron complex, and coated on sand to adsorb FA from synthetic water. Hence, the main objectives of our findings were as follows: (1) to characterize iron-functionalized reduced graphene oxide (fRGO); (2) to explore FA removal by fRGO-coated sand at different FA concentrations, $\mathrm{pH}$ conditions, time, and (3) to evaluate the effect of dose variation of adsorbent such as fRGO coated sand $\left(\sim 0.5-2.5 \mathrm{mg} \mathrm{g}{ }^{-1}\right)$; and (4) to determine the adsorption mechanisms by studying the adsorption kinetics and measuring the isotherms.

\section{Materials and methods}

\section{Chemicals}

The study was conducted using a synthetic solution of fulvic acid (FA), which was a gift by SNEH Corporation, Ahmadabad, India. Graphite powder, concentrated sulfuric acid $\left(\mathrm{H}_{2} \mathrm{SO}_{4}\right)$, sodium nitrate $\left(\mathrm{NaNO}_{3}\right)$, hydrogen peroxide $\left(\mathrm{H}_{2} \mathrm{O}_{2}\right)$, and ferrous sulfate $\left(\mathrm{FeSO}_{4}\right)$ were purchased from Merck, Dermasdat, Germany. Hydrazine hydrate $\mathrm{N}_{2} \mathrm{H}_{4}(50-60 \%)$ and $N, N$-dimethylformamide (DMF) were purchased from Sigma-Aldrich, Taufkirchen, Germany.

\section{Experimental}

\section{Synthesis of reduced graphene oxide from graphene oxide (GO)}

GO was synthesized from graphite powder via Hummers method $^{41,42}$ (Scheme 1). For a typical batch synthesis, graphite powder $(5.0 \mathrm{~g})$ and $\mathrm{NaNO}_{3}(2.5 \mathrm{~g})$ were blended, and $120 \mathrm{~mL}$ of $\mathrm{H}_{2} \mathrm{SO}_{4}(95 \%)$ was poured into a $1.2 \mathrm{~L}$ Borosil glass beaker. Then, the contents were mixed for 30 minutes by a magnetic stirrer in an ice bath. While maintaining vigorous stirring, potassium permanganate $\left(\mathrm{KMnO}_{4}\right)(15.0 \mathrm{~g})$ was added to the suspension. The rate of mixing of $\mathrm{KMnO}_{4}$ was in a very controlled manner to maintain the mixture temperature lower than $20^{\circ} \mathrm{C}$. The ice bath was then detached and the compound was vigorously stirred at $35{ }^{\circ} \mathrm{C}$ for $30 \mathrm{~min}$. During the reaction, the compound gradually became pasty and the color changed to light brown. At the end of the reaction, $150 \mathrm{~mL}$ of $\mathrm{H}_{2} \mathrm{O}$ was added dropwise to the paste under vigorous mixing. The temperature of the system was rapidly increased to $98{ }^{\circ} \mathrm{C}$ that was maintained by external heating for $15 \mathrm{~min}$ and effervescence was observed. After stopped the fumes from the exfoliated paste was cooled for $20 \mathrm{~min}$ in a water bath upon completion of fumes, and $450 \mathrm{~mL}$ of $\mathrm{H}_{2} \mathrm{O}$ was added to stop the oxidation. A $15 \mathrm{~mL}$ aliquot of $30 \% \mathrm{H}_{2} \mathrm{O}_{2}$ was added to the reaction, and the color changed to yellow. For refinement, the mixture was rinsed by separately washing and centrifuging with $10 \% \mathrm{HCl}$ and DI water several times to achieve a $\mathrm{pH}$ value of 7 .

The gray brownish GO powder was dispersed in DI water via (250 $\mathrm{mL} \mathrm{H}_{2} \mathrm{O}$ and $100 \mathrm{mg} \mathrm{GO}$ ) sonication such that no particulate matter was found in the solution (Scheme 1). Hydrazine hydrate $\left(\mathrm{N}_{2} \mathrm{H}_{4}\right)$ was added into the solution and the mixture was heated for $2 \mathrm{~h}$ in an oil bath containing commercial sunflower oil at $100{ }^{\circ} \mathrm{C}$ under magnetic stirring to maintain a homogeneous suspension. Then, the solution was transferred to a water

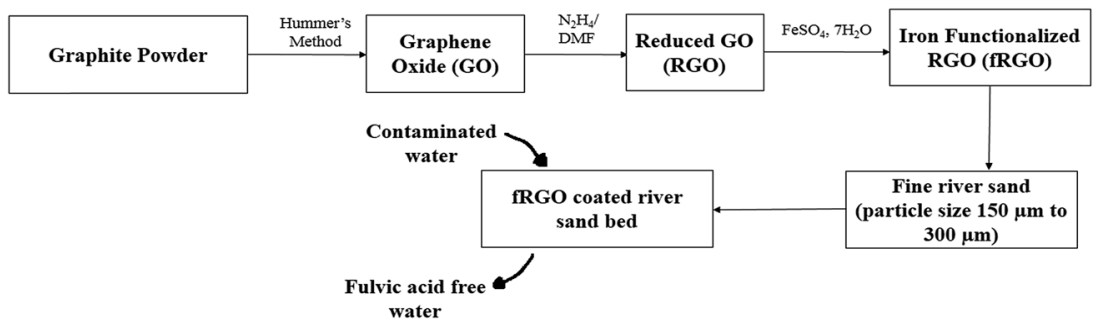

Scheme 1 Flow diagram of fulvic acid removal by iron-functionalized reduced graphene oxide (fRGO). 
cooling condenser. After $24 \mathrm{~h}$, black solids precipitated in the solution as reduced GO. ${ }^{43,44}$

$N, N$-Dimethylformamide (DMF) was added to the abovementioned solution by sonication with a $9: 1$ volume ratio of $\mathrm{DMF} / \mathrm{H}_{2} \mathrm{O}$ for homogenous dispersion of $\mathrm{RGO}$ in the solution. ${ }^{45,46}$ As a result, the RGO solution was concentrated to $20 \mathrm{mg} \mathrm{mL}^{-1}$ for further experiments.

\section{Functionalization of RGO}

RGO (3 mL) solution was dispersed in deionized water (DI) $(147 \mathrm{~mL})$ by ultrasonication for $30 \mathrm{~min}$. To this dispersion, $\mathrm{FeSO}_{4} \cdot 7 \mathrm{H}_{2} \mathrm{O}(15 \mathrm{mg})$ was added. The mixture was agitated for $24 \mathrm{~h}$ at $27^{\circ} \mathrm{C}$. After $24 \mathrm{~h}, 5 \mathrm{~mL}$ of $0.1 \mathrm{~N}$ ammonium hydroxide $\left(\mathrm{NH}_{4} \mathrm{OH}\right)$ was mixed until the $\mathrm{pH}$ reached 8 . Upon addition of ammonium hydroxide, the color of the compound turned brownish-red. The deep brownish-red color signified the formation of ferric hydroxide in the mixture. A hot plate was used to evaporate the water from the compound. After evaporating the water from the mixture, a solid brownish-mass was formed, which was later suspended and washed with warm water several times. This brownish-mass was then dried in a vacuum oven at $85^{\circ} \mathrm{C}$ for $12 \mathrm{~h}$ to complete the functionalization of the RGO nanomaterial. ${ }^{13}$

\section{Coating of sand with fRGO}

Natural sand with particle size that passes through $300 \mu \mathrm{m}$ and retain in $150 \mu \mathrm{m}$ was sieved, collected, and washed with a10\% $\mathrm{HCl}$ solution for the removal of different impurities before use. The acid-washed sand sample was then heated to $550{ }^{\circ} \mathrm{C}$ to remove any organic impurities. It was then cooled down to room temperature and stored in a vacuum desiccator for further use. For coating of RGO on sand particles, $50 \mathrm{~g}$ of this cleaned sand was put into a $250 \mathrm{~mL}$ beaker with $3 \mathrm{~mL}$ of $20 \mathrm{mg} \mathrm{mL}$ RGO. The mixture was then homogenized with $15 \mathrm{mg} \mathrm{FeSO}_{4}$ dissolved in $150 \mathrm{~mL}$ of deionized water and heated up to $15{ }^{\circ} \mathrm{C}$ in a vacuum oven for three hours until nanocomposite was hardly attached on the surface of sand. ${ }^{29}$ Then, the fRGO nanocomposite-coated sand was heated up to $450{ }^{\circ} \mathrm{C}$ in a muffle furnace for the completion of annealing of the compound.

\section{Characterization}

Surface functionalization of fulvic acid (FA) and as-prepared fRGO was verified by FTIR spectroscopy (FTIR BRUKER TENSOR 27, Germany). The surface morphology of fRGOcoated sand was observed by LEICA DMi8 optical microscopy and scanning electron microscopy (HITACHI S-3400N) with EDAX facility (EMAX). The surface morphology of fRGO was additionally evaluated by transmission electron microscopy (TEM, Quanta 200 FEG, FEI Company, USA). Upon adsorption, the surface of the complex interacted with FA and the interaction was observed by atomic force microscopy (AFM, Bruker Dimension Edge AFM-Peak force tapping) in an air medium. ${ }^{47}$ A total organic carbon (TOC) analyzer (vario TOC cube, Germany) was used for the determination of the total organic portion available in FA used as an adsorbate in this study. The determination method was performed as per the guidelines in which the FA sample was subjected to high-temperature catalytic oxidation up to $1200{ }^{\circ} \mathrm{C}$ and a $\mathrm{CO}_{2}$ measurement using a non-dispersive infrared (NDIR) sensor was carried out for TOC.

\section{Fulvic acid (FA) removal study}

Effect of $\mathbf{p H}$. Batch experiments were conducted at different $\mathrm{pH}$ values to estimate the effect of $\mathrm{pH}$ on FA removal. To study the effect of $\mathrm{pH}$ on FA removal, six different solutions with $\mathrm{pH}$ values ranging from $2-12$ were prepared. Then, $1 \mathrm{~g}$ of fRGOcoated sand was added to $25 \mathrm{~mL}$ of $10 \mathrm{mg} \mathrm{L}^{-1}$ of FA synthetic solution. The samples were then shaken for $15 \mathrm{~h}$ at $100 \mathrm{rpm}$ in a shaker. The solutions were then filtered and the effluent FA was measured. The final $\mathrm{pH}$ values of the solutions following FA adsorption were found to achieve the nearest values of equilibrium $\mathrm{pH}$. Similar batch studies were conducted to compare the effect of $\mathrm{pH}$ on $\mathrm{FA}$ removal by powdered activated carbon (PAC).

Effect of time. Batch kinetic studies were conducted with 1 gm functionalized RGO-coated sand in $25 \mathrm{~mL}$ of $10 \mathrm{mg} \mathrm{L}^{-1}$ of FA synthetic solution. The contents were stirred for different times ranging from $30 \mathrm{~min}$ to $40 \mathrm{~h}$. A total of fourteen different samples were obtained at different time intervals and filtered using a $0.45 \mu \mathrm{m}$ filter. ${ }^{\mathbf{1 3 , 4 8 , 4 9}}$ Similar batch kinetic studies were conducted to compare the FA removal performance of fRGO with that of powdered activated carbon (PAC).

\section{Adsorption study}

Batch adsorption studies were conducted with five different doses of fRGO-coated sand in $25 \mathrm{~mL}$ of $10 \mathrm{mg} \mathrm{L}^{-1}$ of FA synthetic solution, and the temperature was maintained at $27{ }^{\circ} \mathrm{C}$. During experimentation, the equivalent TOC content of FA was monitored in each run. The FA concentration was $10 \mathrm{mg} \mathrm{L}^{-1}$ equivalents with the TOC concentration of $4.431 \mathrm{mg} \mathrm{L}^{-1}$. Similar TOC concentration values in surface water (River Hooghly) are also reported by other researchers. ${ }^{50}$ Therefore, in the present study, the initial dose concentration of FA was kept at $10 \mathrm{mg} \mathrm{L}^{-1}$. With the desired amount of adsorbent dose, the contents were stirred for $15 \mathrm{~h}$, and removal efficiencies were determined. Similar batch adsorption studies were conducted to compare the FA removal performance of fRGO with that of powdered activated carbon (PAC). Commercial fulvic acid is a highly soluble and deep brown-colored compound. Since it is difficult to obtain pure FA, the removal of FA was monitored by TOC removal. Raw FA contains $44.31 \%$ TOC, and the functional groups associated with FA were characterized by FTIR analysis. A batch study was conducted to evaluate FA adsorption by fRGO.

Then, six different runs with $100 \mathrm{~mL}$ of FA solution at $10 \mathrm{mg}$ $\mathrm{L}^{-1}$ and different adsorbent doses were carried out. The contents were stirred to achieve equilibrium. The equilibrium time was obtained from the kinetic study, which was approximately $15 \mathrm{~h}$ (95\% removal). The contents were then filtered through $0.45 \mu \mathrm{m}$ Whatman filter paper. The removal efficiency of FA was measured in terms of TOC removal. Since sand was used only as a support material, the adsorption capacity was reported in terms of the active functional adsorbents only. 


\section{Result and discussion}

\section{Characterization of RGO and fRGO}

FTIR study. In a Fourier transform infrared spectroscopy (FTIR) study, a broad peak observed from 3400 to $3500 \mathrm{~cm}^{-1}$ was attributed to the $\mathrm{CH}$ - stretching frequency of FA. For fulvic acid samples, a peak can be seen in this region at around $2940 \mathrm{~cm}^{-1}$. The appearance of this peak could be attributed to the asymmetrical C-H stretching of methyl $\left(-\mathrm{CH}_{3}\right)$ groups present in FA. A sharp peak located in the wavenumber range from 1618 to 1720 $\mathrm{cm}^{-1}$ was observed due to stretching of the carbonyl $\mathrm{C}=\mathrm{O}$ group. This observation explains the higher solubility of FA in water due to presence of a higher number of carboxylic acid groups in FA ${ }^{51}$ (Fig. 1).

FTIR was conducted to evaluate the incorporated functional groups on RGO and fRGO. The IR peak values were compared to the standard table of characteristic IR absorptions. It is clear from Fig. 2 that several functional groups were incorporated in the synthesized nanocomposite. The appearance of this peak could be attributed to the asymmetrical $\mathrm{CH}_{2}$ stretching. A sharp peak located at $1630 \mathrm{~cm}^{-1}$ has been observed due to $\mathrm{C}=\mathrm{C}$ stretching. The peak located at $1120 \mathrm{~cm}^{-1}$ represents a $\mathrm{C}-\mathrm{OH}$ alcoholic group, and that at $800 \mathrm{~cm}^{-1}$ represents the carbonyl $\mathrm{C}=\mathrm{O}$ group stretching, respectively. These results explain the highly functionalized properties present in RGO to bond with multivalent metal ions. ${ }^{52,53}$

To increase the organic adsorption capacity of RGO, ferrous sulfate $\left(\mathrm{FeSO}_{4}\right)$ was added for subsequent functionalization. Thus, from Fig. 2, it was concluded that a broad peak observed around $3403 \mathrm{~cm}^{-1}$ was due to the presence of moisture. Another sharp peak was detected at $1635 \mathrm{~cm}^{-1}$ that justified the presence of $\mathrm{C}=\mathrm{C}$, and a peak at $823 \mathrm{~cm}^{-1}$ signified $\mathrm{C}=\mathrm{O}$ stretching. The most important conclusion was drawn from the peak at $1134 \mathrm{~cm}^{-1}$ $\left(1123-1173 \mathrm{~cm}^{-1}\right)$, which is due to the presence of a sulfate $\left(\mathrm{SO}_{4}{ }^{2-}\right)$ ion. This was due to the fact that functionalization occurred

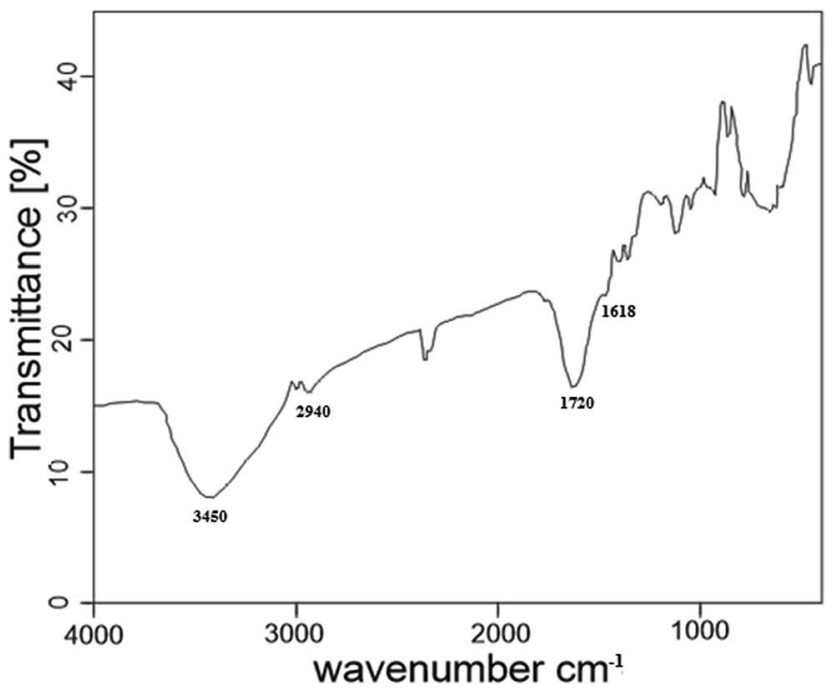

Fig. 1 Fourier transform infrared spectroscopy (FTIR) spectrum of fulvic acid (FA).

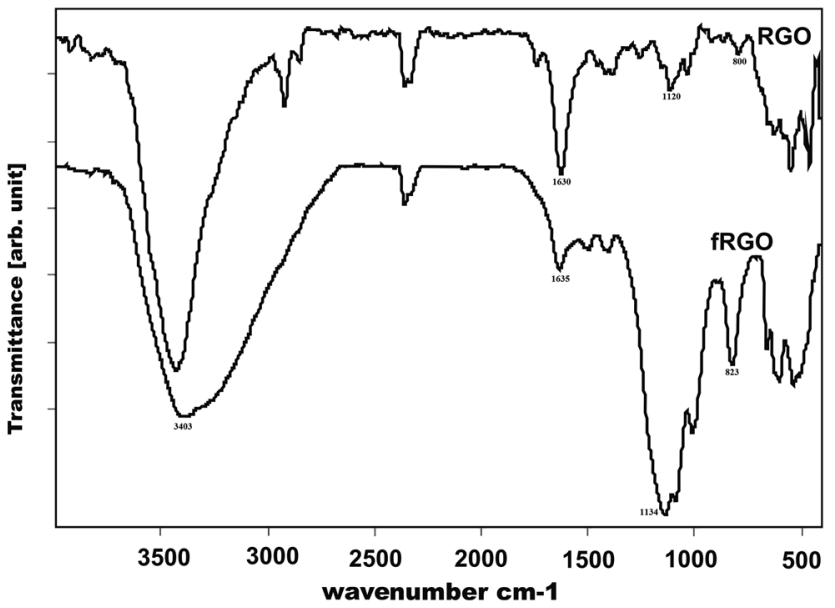

Fig. 2 Fourier transform infrared spectroscopy (FTIR) spectra of RGO and $\mathrm{fRGO}$.

through $\mathrm{FeSO}_{4}{ }^{54}$ The presence of $\mathrm{SO}_{4}{ }^{2-}$ indirectly corroborates the presence of $\mathrm{Fe}$ in functionalized RGO.

The inner double bond oxygen (-O-) and hydroxyl $(-\mathrm{OH}-)$ bond were greatly reduced during the conversion of GO to RGO. ${ }^{55}$ An electrostatic bond was developed between the functionalized iron and a double bond oxygen in the fRGO structure (Scheme $2(\mathrm{a}-\mathrm{i})){ }^{56}$ and the electrostatic bonds are proposed in Scheme 2(aii). ${ }^{57}$ The outer radicals of FA formed the electrostatic bond with a free electron of fRGO, and this bond and $\pi-\pi$ interaction bonds were responsible for the adsorption (Scheme 2(b)). ${ }^{57}$

Optical microscopy study. A uniform dispersion of RGO nanoparticles or flakes was observed in the optical microscopy images at $40 \times$ magnification. This indicates the formation of RGO nanoparticles, and hence the successful formation of RGO (Fig. 3). A magnified image for RGO nanoflakes is presented at the right side of the figure. An internal network within RGO nanoflakes can be easily observed in this specific image. Upon addition of $\mathrm{FeSO}_{4}$, the images became opaque, as observed through the optical microscope, and these images were further evaluated using SEM and TEM.

\section{Scanning electron microscopy (SEM)}

Scanning electron microscopy (SEM) was used for characterizing the morphology of the fRGO composite-coated sand. Sand samples before fRGO coating had a bright morphology (Fig. 4). After coating with an fRGO sheet-like structure, the morphology changed to a dull, glossy look due to the sticky covering over the surface and formation of aggregated clusters (Fig. 4). To understand the elemental composition of the material, the composite was analyzed using $\operatorname{EDAX}$ (Fig. 4), where it was shown that the major elements present were carbon, silicon, and oxygen. The inset in Fig. 4 shows the SEM image of a dry sand particle and the corresponding elemental maps. The observed $\mathrm{Si}$ and $\mathrm{O}$ peaks were resulted from the presence sand $\left(\mathrm{SiO}_{2}\right)$ particles. Whereas the appearance of carbon (C) and aluminum (Al) peaks indicates the presence of reduced graphene oxide, and small amount of impurity subsequently before 


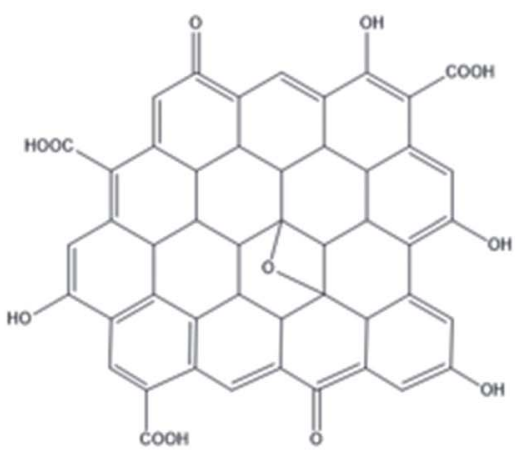

RGO

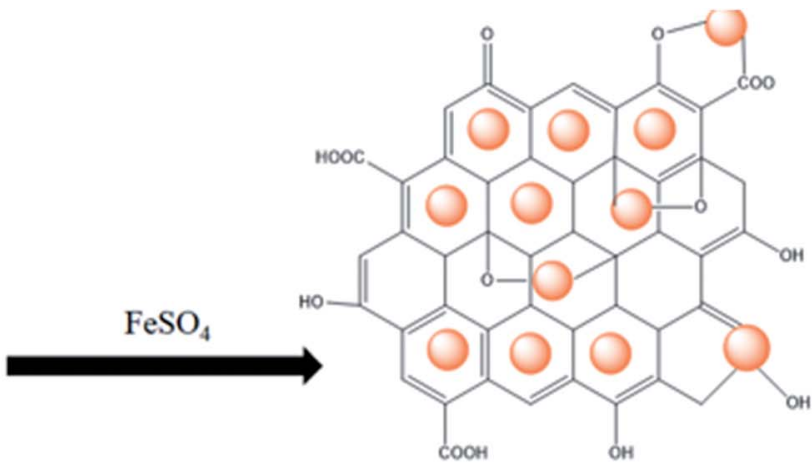

[i] fRGO

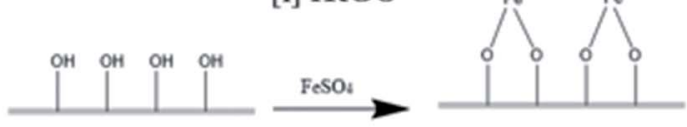

[ii] Electrostatic bond between Fe with RGO

(a) RGO to fRGO conversion by adding $\mathrm{FeSO}_{4}$

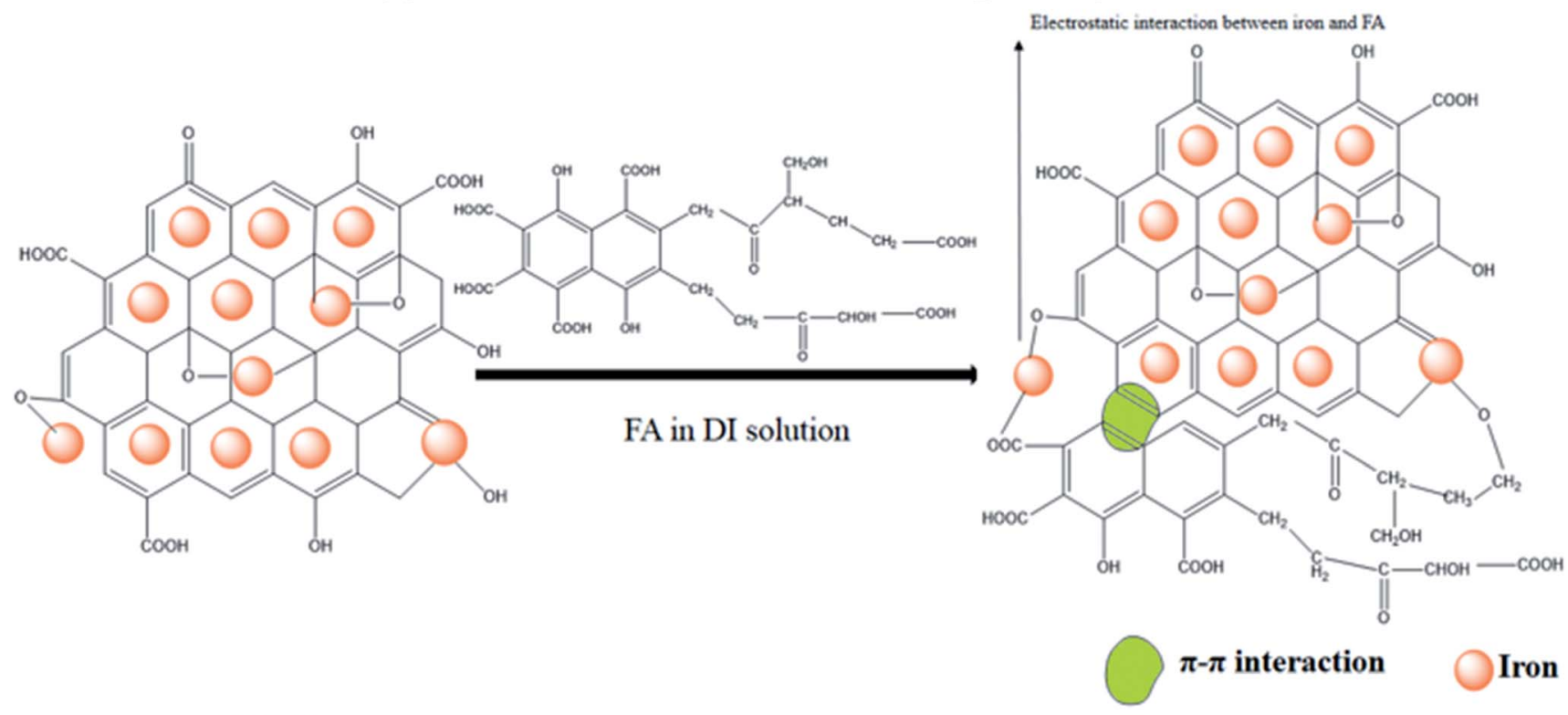

fRGO

(b) Proposed FA-fRGO interaction complex

fRGO-FA complex

Scheme 2 Schematic ( $a$ and $b$ ) of the details proposed for FA-fRGO interaction.
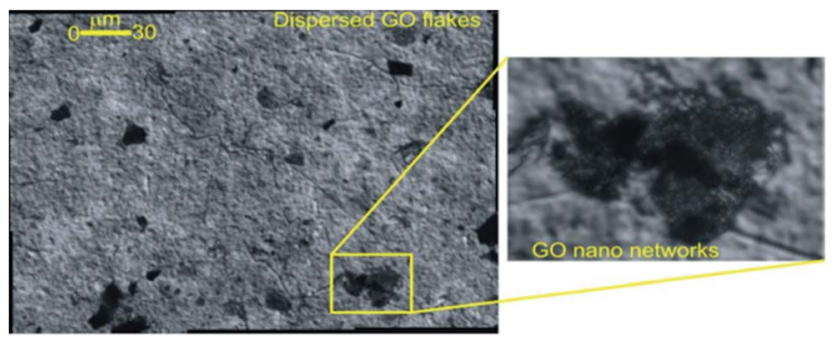

Fig. 3 Optical microscopy images for the presence of a nanostructure in RGO.

heat treatment. However, as observed from Fig. 4, it was expected that after mixing the fRGO compound with sand particles, followed by a heat treatment at $105^{\circ} \mathrm{C}$ and $450{ }^{\circ} \mathrm{C}$, the carbon amount was found increased. Similarly, the EDX graph in the Fig. 4(f) indicates the presence of Fe that confirms the successful coating of sand surface with fRGO. ${ }^{58}$ The elemental composition of the material was analyzed using EDAX to determine the nature of the composite, revealing that true functionalization occurred (Fig. 4).

\section{Transmission electron microscopy (TEM)}

The morphological structure of fRGO was observed using TEM. The layered structure (Fig. 5(a)) and flake-like orientation (Fig. 5(b)) of fRGO are shown in Fig. 5. It shows successful transformation of RGO from GO upon chemical reduction followed by subsequent functionalization with an iron complex. RGO flakes, with a curtain-like structure with nanodimensions, 

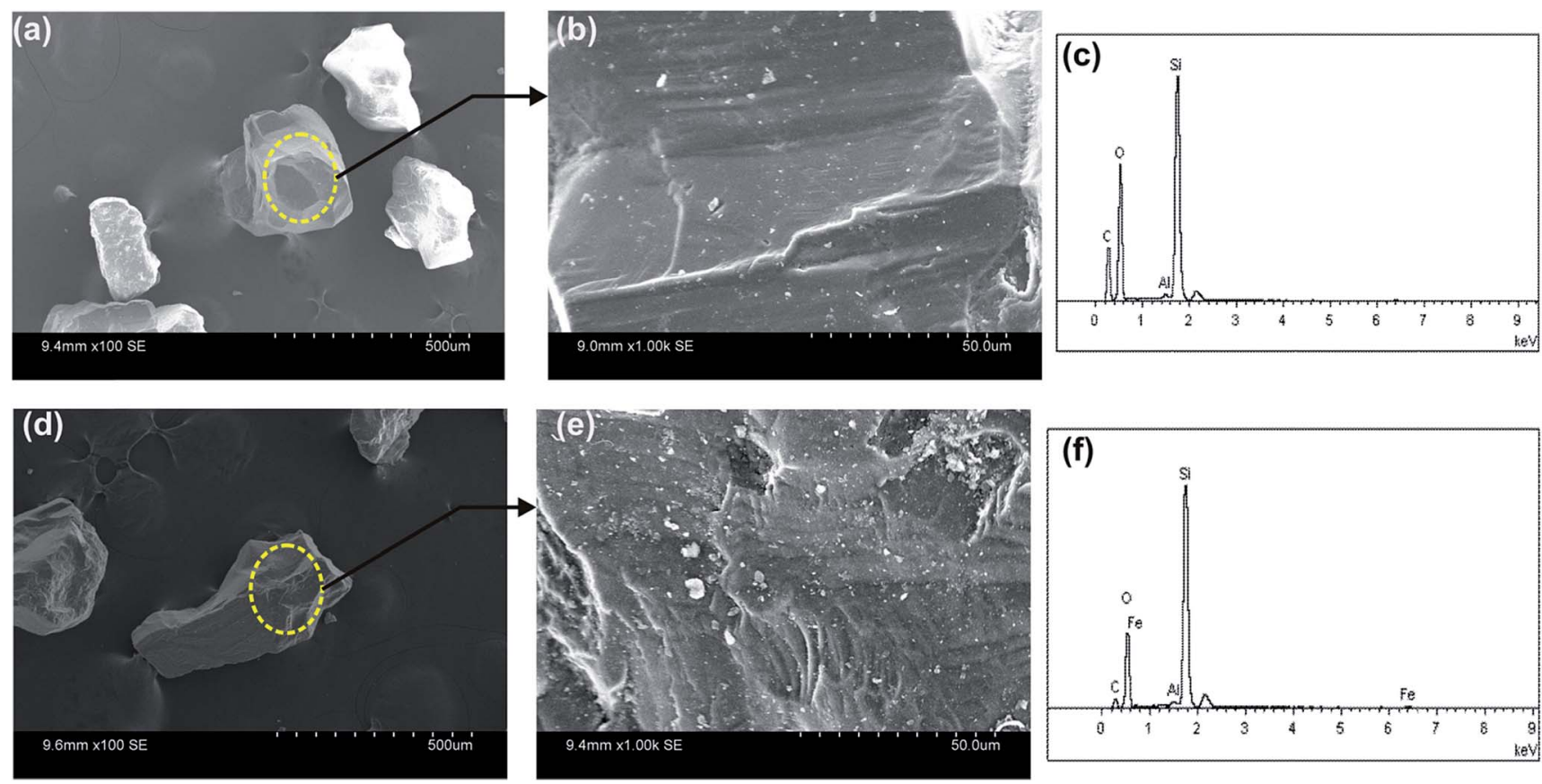

Fig. 4 Scanning electron microscopy (SEM) and energy-dispersive X-ray spectroscopy (EDX) images. (a) Typical surface of sand, (b) enlarged surface of sand, (c) EDX image of sand surface, (d) fRGO coated, sand surface, (e) fRGO coated, enlarged sand surface, (f) EDX image of fRGO coated, sand surface.

clearly indicate very good exfoliation of graphite during the oxidation process. ${ }^{58,59}$ However, the fRGO solution may impart a higher concentration in solution, and therefore, the layered sheet-like structure may appear (Fig. 5(a)). The surface

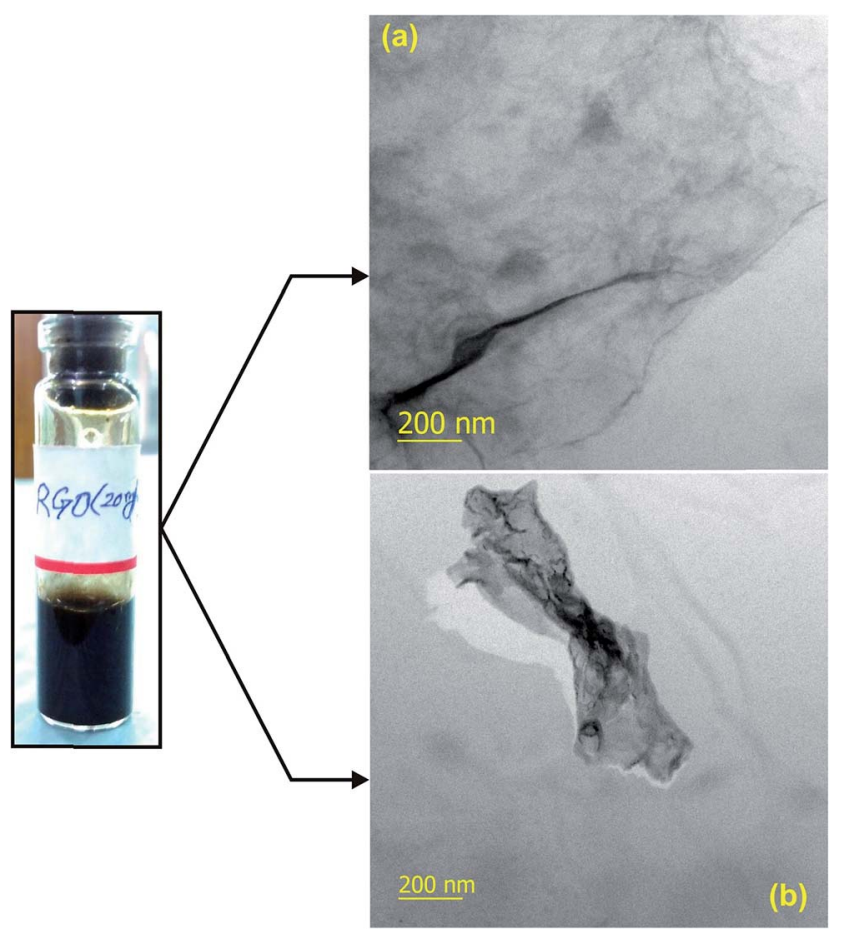

Fig. 5 Transmission electron microscopy (TEM) image of reduced graphene oxide (RGO). (a) Layer of synthesized RGO and (b) single flake of synthesized RGO. morphology of the layered orientation strongly resembles an overlapped structure rather than an aggregated structure. ${ }^{60}$

\section{Atomic force microscopy (AFM)}

To ascertain the adsorption of FA on fRGO, a microtopography study was performed via atomic force microscopy (AFM). A fulvic acid (FA) sample was dissolved in DI water and adsorbed on fRGO at neutral $\mathrm{pH}$. A silicon wafer was taken as a substrate for spin casting of a dried FA-fRGO sample at $27^{\circ} \mathrm{C}$ for $30 \mathrm{~min}$. Fig. 6(a) and (b) shows a plan and sectional profile of FAadsorbed fRGO flakes. Due to adsorption, the molecules formed in the FA-fRGO interaction featured a particle or bulbshaped structure (Fig. 6(a)). The dimensions for white spots or knots, with a horizontal length of $10-40 \mathrm{~nm}$ and a vertical height of 2-12 nm, were tightly dispersed on the silicon wafer top surface. It can be clearly observed in Fig. 6(a) that smaller particles of complex formed by FA adsorbed fRGO remain in the height of $\sim 2 \mathrm{~nm},{ }^{61}$ and larger particles of FA-fRGO complex show the height of $\sim 12 \mathrm{~nm}$. Interestingly the larger particles were found to aggregate at the outer region due to the existing. centrifugal force. $^{62}$

\section{Removal study}

Effect of pH. Fig. 7 represents the removal of FA for both adsorbents. It is clear that FA removal increased at low $\mathrm{pH}$ and decreased at high $\mathrm{pH}$ for both adsorbents. Reduced graphene oxide-iron nanocomposites are reported to have a $\mathrm{pH}_{\mathrm{pzc}}$ value about 4.5. ${ }^{13}$ At low $\mathrm{pH}$, the FA molecule remained undissociated and became hydrophobic. At low $\mathrm{pH}$, fRGO became positively charged and could attract undissociated FA by induction. The 

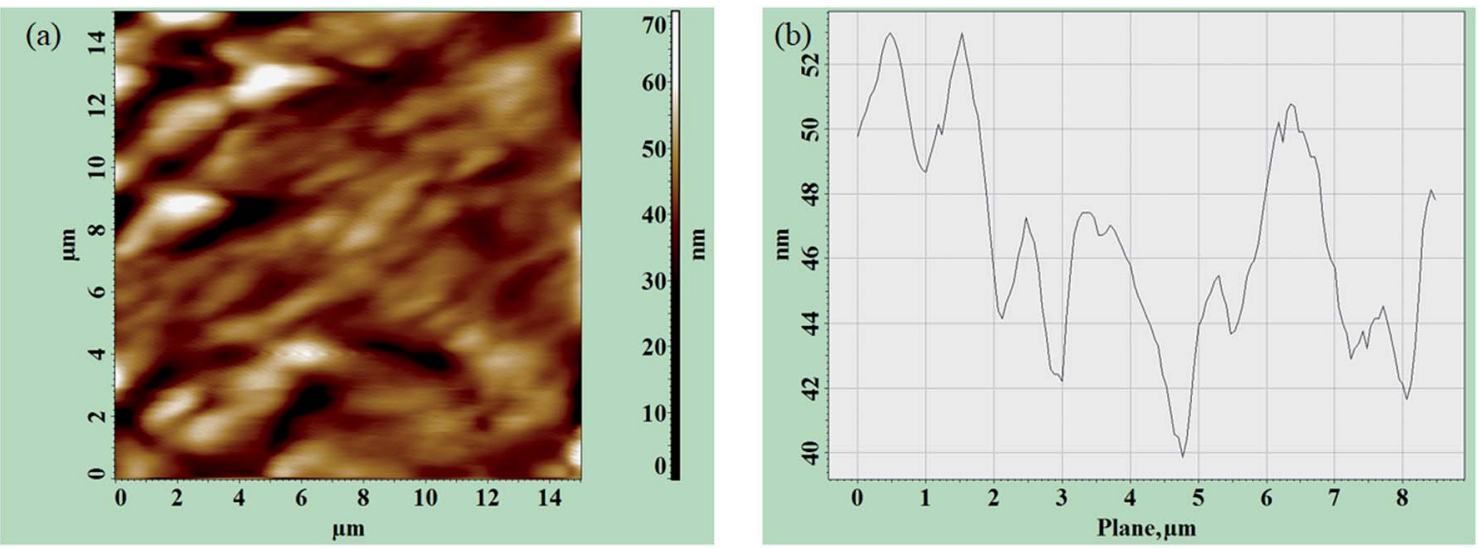

Fig. 6 FA-fRGO interaction: (a) surface microtopology and (b) depth profile.

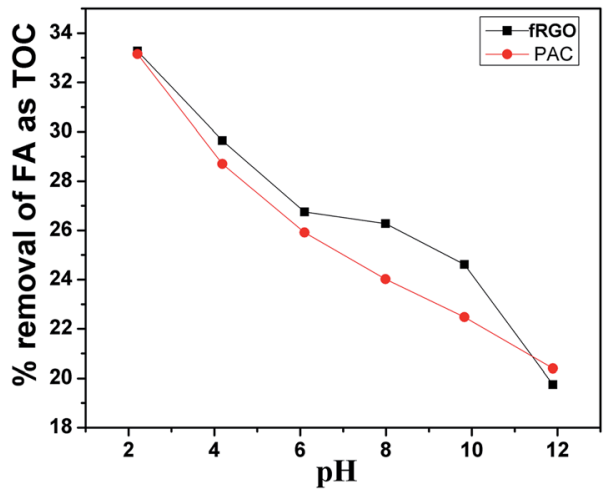

Fig. 7 Percentage (\%) removal of FA (as TOC) vs. $\mathrm{pH}$ of solutions measured after adsorption of FA by fRGO and PAC.

hydrophobicity of FA at low $\mathrm{pH}$ and simultaneous development of positive charges on fRGO enhanced the FA removal. At higher $\mathrm{pH}$, the intra- and intermolecular electrostatic repulsive forces in the FA molecule increased. Moreover, the fRGO surface became negatively charged and subsequently the removal decreased..$^{13,48}$ Similar results of a higher removal of FA at low $\mathrm{pH}$ by an iron-functionalized nanocarbon composite have been reported by other researchers. ${ }^{\mathbf{1 3 , 4 8 , 4 9 , 6 3}}$

Effect of contact time. A kinetics study was performed to determine the time-dependent removal of the adsorbate. It is clear

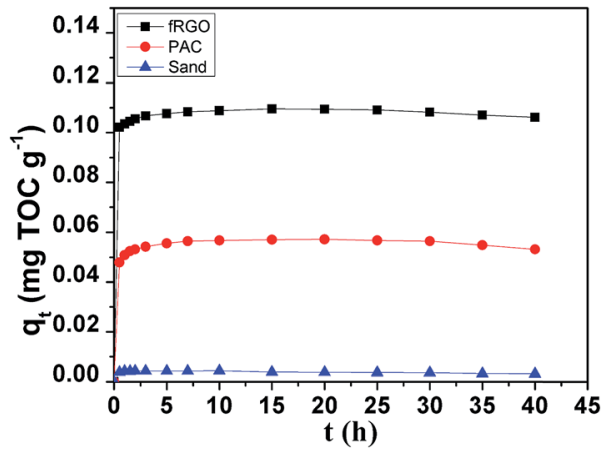

Fig. 8 Effect of contact time on the adsorption of FA by the adsorbents fRGO, PAC, and sand. from Fig. 8 that the kinetic performance of the three adsorbents fRGO, PAC, sand were in the order of fRGO $>$ PAC $>$ sand. Within the initial $5 \mathrm{~h}$ of contact time, all the adsorbents attained adsorption equilibrium. After increasing the contact time beyond $5 \mathrm{~h}$, no significant increase in removal was observed. It is clear from Fig. $8\left(t v s . q_{t}\right)$ that within the initial $1.5 \mathrm{~h}$, more than $90 \%$ of TOC was removed by fRGO. However, PAC and sand removed 45.5 and $3.62 \%$ TOC, respectively. At equilibrium, fRGO achieved an adsorption capacity of $0.11 \mathrm{mg} \mathrm{g}^{-1}$, whereas the adsorption capacity of PAC and sand was found to be $0.055 \mathrm{mg} \mathrm{g}^{-1}$ and $0.002 \mathrm{mg} \mathrm{g}^{-1}$, respectively. fRGO has a 2 and 55 times higher adsorption capacity compared to PAC and clean sand, respectively. The higher adsorption of TOC by fRGO was due to the higher surface area of fRGO compared to that of PAC and sand. The higher removal was also attributed to the presence of active functional groups attached on the fRGO.

The FA removal data was also plotted according to four different kinetic models: pseudo- $1^{\text {st }}$ order, pseudo- $2^{\text {nd }}$ order, the Elovich model, and the intraparticle-diffusion kinetic model. The four types of models are described as follows.

(1) Pseudo- $1^{\text {st }}$ order model:

$$
\log \left(q_{\mathrm{e}}-q_{t}\right)=\log q_{\mathrm{e}}-k_{\mathrm{s} 1} t
$$

(2) Pseudo-2 $2^{\text {nd }}$ order model:

$$
\frac{t}{q_{t}}=\frac{1}{q_{\mathrm{e}}^{2} k}+\frac{t}{q_{\mathrm{e}}}
$$

(3) Elovich model:

$$
q_{t}=\frac{1}{\beta} \ln (\alpha \beta)+\frac{1}{\beta} \ln t
$$

(4) Intraparticle diffusion kinetic model:

$$
q_{t}=k_{\text {diff }} t^{\frac{1}{2}}+C
$$

where $q_{\mathrm{e}}$ and $q_{t}\left(\mathrm{mg} \mathrm{g}^{-1}\right)$ are the adsorbed amounts of FA on the adsorbent at equilibrium and at time $t(\mathrm{~h})$, respectively. The variables $k_{\mathrm{s} 1}$ and $k_{\mathrm{s} 2}\left(\mathrm{mg} \mathrm{h} \mathrm{g}^{-1}\right)$ are the pseudo- $1^{\text {st }}$-order and 
(a)

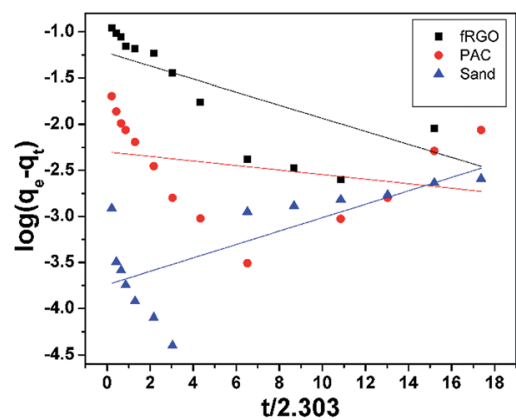

(c)

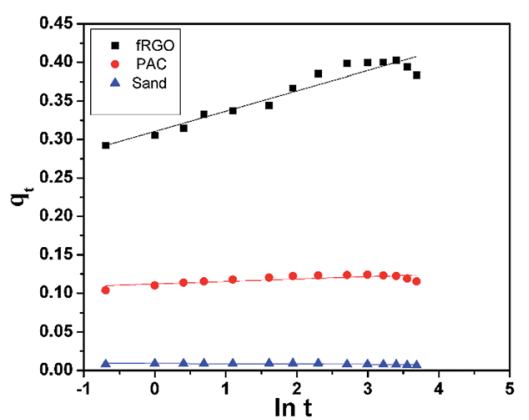

(b)

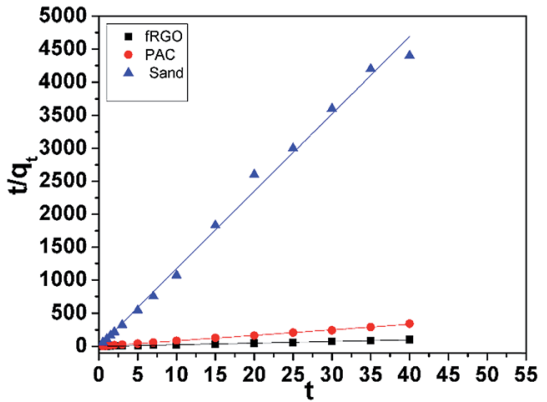

(d)

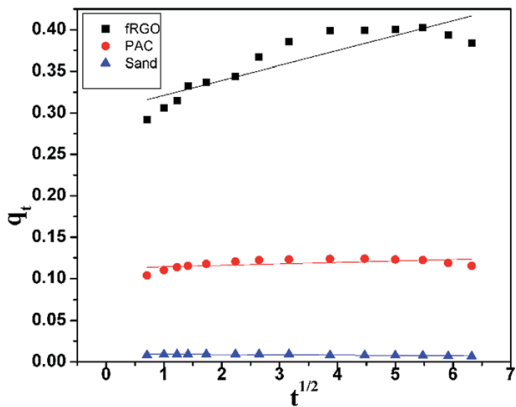

Fig. 9 Effect of contact time on the removal efficiency: pseudo- $1^{\text {st }}$-order kinetics (a), pseudo-2 ${ }^{\text {nd }}$-order kinetics (b), Elovich kinetics (c) and intraparticle diffusion kinetics (d) for adsorption of FA onto fRGO, PAC, and sand $\left(C_{0}=10 \mathrm{mg} \mathrm{L}^{-1}, C_{0}\right.$ as per TOC $=4.431 \mathrm{mg} \mathrm{L}-1, V=25 \mathrm{~mL}$, $t=40 \mathrm{~h}$, temperature of $300 \mathrm{~K})$.

Table 1 Correlation coefficients and constants for the kinetic models are given for FA adsorption by fRGO, PAC, and sand

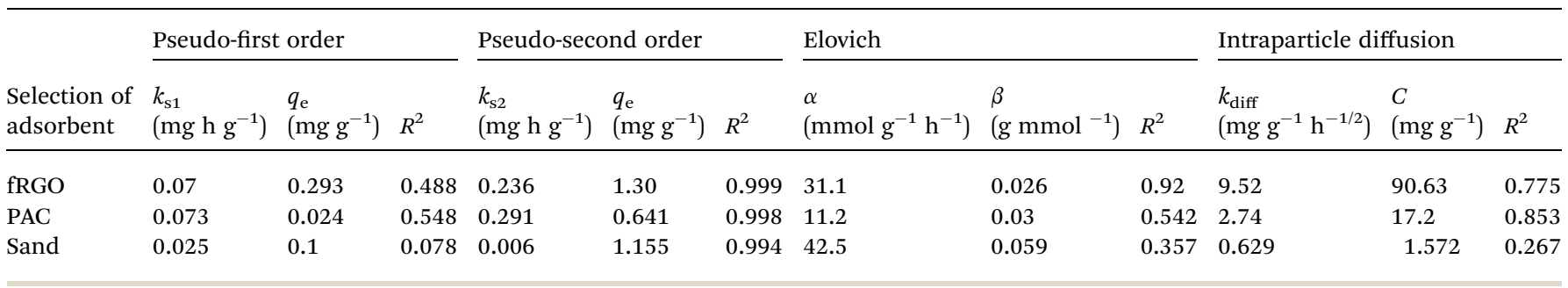

pseudo- $2^{\text {nd }}$-order rate constants. The variable $\alpha\left(\mathrm{mmol} \mathrm{g}^{-1} \mathrm{~h}^{-1}\right)$ is the initial adsorption rate, and $\beta\left(\mathrm{g} \mathrm{mmol}^{-1}\right)$ is the desorption constant. The variable $k_{\text {diff }}\left(\mathrm{mg} \mathrm{g}^{-1} \mathrm{~h}^{-1 / 2}\right)$ is the intraparticle diffusion rate constant, and $C$ is a constant $\left(\mathrm{mg} \mathrm{g}^{-1}\right)$.

Only a pseudo- $2^{\text {nd }}$-order model with respect to $t / q_{\mathrm{t}} v s$. $t$ showed a straight line fit of the experimental data-points, as observed by other researchers. ${ }^{37,40,64}$ The removal of TOC (FA) by the three adsorbents is plotted in Fig. 9(a)-(d). It is clear from the figures that all three adsorbent materials showed an excellent fit to the pseudo-second order kinetic model. Correlation coefficients and constants for the kinetic models are given in Table 1 for FA adsorption by fRGO, PAC, and sand. The kinetic coefficients calculated for the three adsorbents fRGO, PAC, and sand are $8.1596 \mathrm{~h}^{-1}, 44.763 \mathrm{~h}^{-1}$ and $15881.56 \mathrm{~h}^{-1}$, respectively. The equilibrium adsorption capacity for TOC removal by fRGO, PAC, and sand were calculated from the model and found to be $0.399 \mathrm{mg} \mathrm{g}^{-1}, 0.1196 \mathrm{mg} \mathrm{g}^{-1}$, and $0.00853 \mathrm{mg} \mathrm{g}^{-1}$, respectively. The equilibrium adsorption capacity of fRGO was found to be
3.34 and 46.78 times higher compared to that of PAC and sand, respectively. A similar removal performance of FA by different carbonaceous adsorbents has been reported elsewhere. ${ }^{13,48,49,63,65-68}$ From these results, it was concluded that fRGO and PAC had a preferable adsorption capability, whereas sand had no such ability to remove FA from the solution. Because EDAX (Fig. 4) analysis of sand particles revealed the presence of aluminum, the small amount of TOC removal by sand particles may be attributed to the presence of aluminum as a mineralogical composition with the sand particles. The presence of carboxylic and phenolic functional groups in FA helped in its adsorption by coordinative interaction with aluminum oxide or hydroxide and thereby showed a small amount of TOC removal by sand. Fulvic acid was adsorbed at the solid-water interface due to their hydrophobic interaction, ${ }^{69}$ and the presence of acidic oxides $\left(\mathrm{SiO}_{2}\right)$ enhanced the uptake of humic substances via lowering the $\mathrm{pH}^{70}$ 
(a)

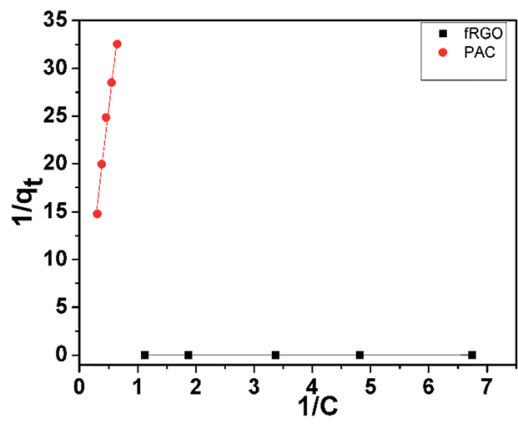

(b)

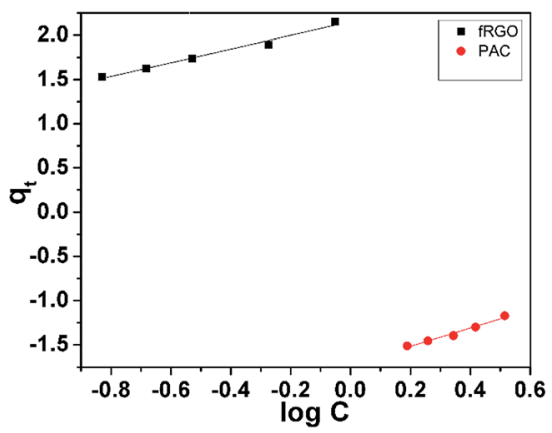

Fig. 10 Langmuir (a) and Freundlich (b) adsorption isotherm fit of FA onto adsorbents fRGO and PAC, respectively $\left(C_{0}=10\right.$ mg $L^{-1}, C_{0}$ as per $\mathrm{TOC}=4.431 \mathrm{mg} \mathrm{L}^{-1}, \mathrm{~V}=25 \mathrm{~mL}$, contact time for $15 \mathrm{~h}, \mathrm{pH}$ at 7 , and temperature of $300 \mathrm{~K}$ ).

Table 2 The factors and correlation coefficients for Langmuir and Freundlich isotherms are given for FA adsorption by fRGO and PAC

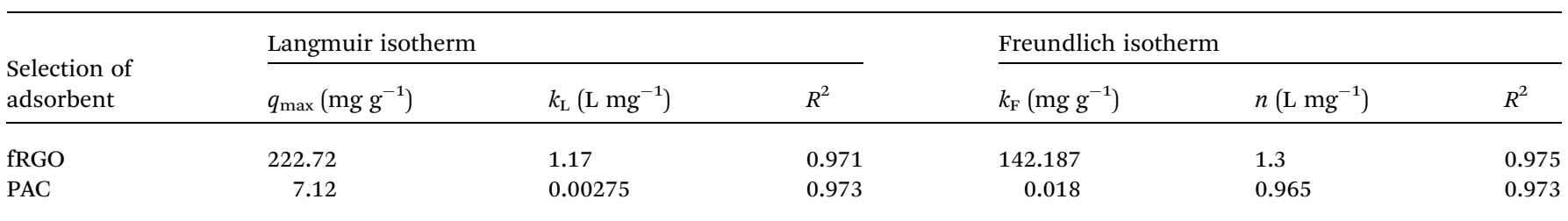

\section{Adsorption isotherms}

Two basic adsorption isotherms, namely Langmuir and Freundlich adsorption isotherms, were investigated for FA removal by fRGO, and the adsorption performance was compared with that of PAC.

\section{Langmuir adsorption isotherm}

The Langmuir adsorption isotherm is applicable to characterize monolayer adsorption morphology, covering a limited number of identical locations. ${ }^{13}$ The model was adopted for a constant intensity of adsorption morphology and restricted the movement of adsorbate through the surface. The Langmuir adsorption isotherm may be represented in a linear form by the following equation:

$$
1 / q_{\mathrm{e}}=1 /\left(q_{\max } C_{\mathrm{e}} k_{\mathrm{L}}\right)+1 / q_{\max }
$$

where $C_{\mathrm{e}}$ is the equilibrium solute concentration $\left(\mathrm{mg} \mathrm{L}^{-1}\right), q_{\mathrm{e}}$ is the equilibrium sorption capacity $\left(\mathrm{mg} \mathrm{g}^{-1}\right), q_{\max }$ is the maximum sorption capacity $\left(\mathrm{mg} \mathrm{g}^{-1}\right)$, and $k_{\mathrm{L}}$ is the Langmuir constant related to the intensity of adsorption $\left(\mathrm{L} \mathrm{mg}^{-1}\right)$. The Langmuir isotherm model for the removal of FA by fRGO and PAC is presented in Fig. 10(a). The adsorption isotherm constants for both the materials and the isotherms are shown in Table 2. It is clear from Fig. 10(a) that both materials obeyed the Langmuir isotherm. However, the maximum adsorption capacity $\left(q_{\max }\right)$ of fRGO was found to be $222.72 \mathrm{mg} \mathrm{g}^{-1}$, whereas PAC had the maximum adsorption capacity equal to $7.12 \mathrm{mg} \mathrm{g}^{-1}$. Although both materials fit well $\left(R^{2}\right.$ of $\mathrm{fRGO}=0.995$ and for $\left.\mathrm{PAC}=0.974\right)$ for FA removal, fRGO was about 31 times more efficient than PAC. The values of $q_{\mathrm{e}}$ and $k_{\mathrm{L}}$ were computed from the slope and intercept from the Langmuir isotherm plot, and the $R^{2}$ values were
0.971 and 0.974 , verifying that the sorption data matched well with the Langmuir isotherm model for fRGO and PAC, respectively $^{\mathbf{1 3 , 4 8 , 5 2 , 7 1}}$ (Fig. 10(a)). The values of $k_{\mathrm{L}}$ for fRGO and PAC were found to be $1.17 \mathrm{~L} \mathrm{mg}^{-1}$ and $0.00275 \mathrm{~L} \mathrm{mg}^{-1}$, respectively.

\section{Freundlich adsorption isotherm}

The adsorption characteristics of a heterogeneous surface with low and intermediary concentrations can be described by a Freundlich adsorption isotherm. ${ }^{13}$ The experimental adsorption data were tested via a Freundlich isotherm. The Freundlich isotherm may be expressed in the following linear form:

$$
\log q_{\mathrm{e}}=\log k_{\mathrm{F}}+1 / n \log C_{\mathrm{e}}
$$

where $q_{\mathrm{e}}$ is the equilibrium sorption capacity $\left(\mathrm{mg} \mathrm{g}^{-1}\right), k_{\mathrm{F}}$ is the adsorption capacity $\left(\mathrm{mg} \mathrm{g}^{-1}\right), n$ is the adsorption intensity ( $\mathrm{L}$ $\left.\mathrm{g}^{-1}\right)$, and $C_{\mathrm{e}}$ is the equilibrium concentration $\left(\mathrm{mg} \mathrm{L}^{-1}\right)$.

The Freundlich adsorption isotherm for two adsorbents is shown in Fig. 10(b). It is clear from Fig. 10(b) that both adsorbents showed a good fit to the model. The sorption capacity of fRGO was found to be $142.19 \mathrm{mg} \mathrm{g}^{-1}$, whereas PAC showed an FA adsorption capacity of about $0.02 \mathrm{mg} \mathrm{g}^{-1}$, which was significantly low. The low removal of FA by PAC may be attributed to the fact that high molecular weight, large sized FA does not get adsorbed on PAC due to its small pore size. Due to functionalization of reduced graphene oxide, the adsorption capacity of FA significantly increased. The adsorption isotherm constants for both materials and the isotherms are shown in Table 2.

The correlation coefficients $\left(R^{2}\right)$ for the Freundlich isotherm model for both the adsorbents (fRGO and PAC) were higher than those for the Langmuir isotherm model. The results demonstrated that heterogeneous surface adsorptions occurred at low and intermediate concentrations of adsorbate. Hence, 
Table 3 Values of the thermodynamic parameter for fulvic acid (FA) sorption on $\mathrm{RRGO}$ and PAC at $27^{\circ} \mathrm{C}(300 \mathrm{~K})$

\begin{tabular}{ll}
\hline Selection of adsorbent & Free energy $\left(\Delta G^{\circ}\right)\left(\mathrm{J} \mathrm{mol}^{-1}\right)$ \\
\hline fRGO & -391.6 \\
PAC & -284.2
\end{tabular}

the primary mechanism of adsorption in this case is driven by the heterogeneous surfaces of the adsorbent. ${ }^{49,63}$

The thermodynamic parameter of free energy change $\Delta G^{\circ}$ was calculated from the temperature-dependent sorption isotherms. ${ }^{13}$ The equilibrium constant $K^{0}$ and $\Delta G^{\circ}$ were derived from the relationship:

$$
\Delta G^{\circ}=-R T \ln K^{\circ}
$$

The results of free energy change $\Delta G^{\circ}$ are shown in Table 3 . The negative values of $\Delta G^{\circ}$ signified that both the Langmuir and Freundlich adsorption processes were spontaneous. ${ }^{37,38}$

\section{Conclusions}

The present study indicates that iron-functionalized reduced graphene oxide (fRGO) can be used as an effective adsorbent material for the removal of contaminants such as fulvic acid. The removal of FA is pH-dependent, and higher removal takes place at low $\mathrm{pH}$. The kinetic study of FA removal revealed that it followed a second-order kinetics model better compared to firstorder kinetics. Functionalization of RGO by an iron salt enhanced the FA adsorption capacity. Due to the large specific surface area and functionalization of RGO, adsorption of FA greatly increased compared to that by powder activated carbon (PAC). Our results suggest that fRGO is an effective adsorbent for removing fulvic acid (FA) molecules in surface water environments. Both the electrostatic bond with a free electron of fRGO and the $\pi-\pi$ interaction bonds were responsible for the adsorption. This also suggests a new way to improve the adsorption capacity of RGO for the removal of natural organic materials in water.

\section{Acknowledgements}

The authors would like to acknowledge Mr Praveen Sawai, Technical Assistant, Materials Science Centre, Indian Institute of Technology Kharagpur (IIT, KGP) for helping us with FTIR analyses. We would also like to thank Dr Diptonil Banerjee, Assistant Professor, Dr M. N. Dastur School of Materials Science and Engineering, for helping with AFM analyses.

\section{References}

1 S. A. Baghoth, S. K. Sharma and G. L. Amy, Tracking natural organic matter (NOM) in a drinking water treatment plant using fluorescence excitation-emission matrices and PARAFAC, Water Res., 2011, 45(2), 797-809.
2 K. M. Elkins and D. J. Nelson, Fluorescence and FT-IR spectroscopic studies of Suwannee river fulvic acid complexation with aluminum, terbium and calcium, $J$. Inorg. Biochem., 2001, 87(1-2), 81-96.

3 S. W. Krasner, H. S. Weinberg, S. D. Richardson, S. J. Pastor, R. Chinn, M. J. Sclimenti, G. D. Onstad and A. D. Thruston Jr, Occurrence of a New Generation of Disinfection Byproducts, Environ. Sci. Technol., 2006, 40(23), 7175-7185.

4 P. C. Singer, DPBs in Drinking Water, J.-Am. Water Works Assoc., 2006, 98, 73-79.

5 A. Matilainen, M. Vepsalainen and M. Sillanpaa, Removal of natural organic matter from drinking water by advanced oxidation, Adv. Colloid Interface Sci., 2010, 159, 189-197.

6 Q. Zhou, Y. H. Zhong, X. Chen, J. H. Liu, X. J. Huang and Y. C. Wu, Adsorption and photocatalysis removal of fulvic acid by $\mathrm{TiO}_{2}$-graphene composites, J. Mater. Sci., 2014, 49, 1066-1075.

7 S. Zhang, X.-Y. Li and J. P. Chen, Preparation and evaluation of a magnetite-doped activated carbon fiber for enhanced arsenic removal, Carbon, 2010, 48, 60-67.

8 S. C. Smith and D. F. Rodrigues, Carbon-based nanomaterials for removal of chemical and biological contaminants from water: A review of mechanisms and applications, Carbon, 2015, 91, 122-143.

9 A. Kaur and U. Gupta, A review on applications of nanoparticles for the preconcentration of environmental pollutants, J. Mater. Chem., 2009, 19, 8279-8289.

10 N. Savage and M. S. Diallo, Nanomaterials and water purification: Opportunities and challenges, J. Nanopart. Res., 2005, 7(4), 331-342.

11 M. M. Khin, S. Nair, V. J. Babu, R. Murugan and S. Ramakrishna, A review on nanomaterials for environmental remediation, Energy Environ. Sci., 2012, 5, 8075-8109.

12 A. K. Geim and K. S. Novoselov, The rise of graphene, Nat. Mater., 2007, 6, 183-191.

13 J. Li, S. Zhang, C. Chen, G. Zhao, X. Yang, J. Li and X. Wang, Removal of $\mathrm{Cu}(\mathrm{II})$ and Fulvic Acid by Graphene Oxide Nanosheets Decorated with $\mathrm{Fe}_{3} \mathrm{O}_{4}$ Nanoparticles, ACS Appl. Mater. Interfaces, 2012, 4(9), 4991-5000.

14 J. R. Potts, D. R. Dreyer, C. W. Bielawski and R. S. Ruoff, Graphene-based polymer nanocomposites, Polymer, 2011, 52(1), 5-25.

15 M. Terrones, O. Martin, M. González, J. Pozuelo, B. Serrano, J. C. Cabanelas, S. M. V. Díaz and J. Baselga, Interphases in Graphene Polymer-based Nanocomposites: Achievements and Challenges. 2011, vol. 23, 44, pp. 5302-5310.

16 C. Shan, H. Yang, D. Han, Q. Zhang, A. Ivaska and L. Niu, Langmuir, 2009, 25(20), 12030-12033.

17 Y. Zhu, D. K. James and J. M. Tour, New Routes to Graphene; Graphene Oxide and Their Related Applications, Advanced Materials Reviews, 2012, 24(36), 4924-4955.

18 T. Kuila, S. Bose, A. K. Mishra, P. Khanra, N. H. Kim and J. H. Lee, Chemical functionalization of graphene and its applications, Prog. Mater. Sci., 2012, 57(7), 1061-1105. 
19 J. Guo, R. Wang, W. W. Tjiu, J. Pan and T. Liu, Synthesis of Fe nanoparticles@graphene composites for environmental applications, J. Hazard. Mater., 2012, 225-226, 63-73.

20 V. K. Gupta, B. Gupta, A. Rastogi, S. Agarwal and A. Nayak, Pesticides removal from waste water by activated carbon prepared from waste rubber tire, Water Res., 2011, 45(13), 4047-4055.

21 Y. He, L. Huang, J. S. Cai, X. M. Zheng and S. G. Sun, Structure and electrochemical performance of nanostructured $\mathrm{Fe}_{3} \mathrm{O}_{4}$ /carbon nanotube composites as anodes for lithium ion batteries, Electrochim. Acta, 2010, 55, 1140-1144.

22 V. Singh, D. Joung, L. Zhaia, S. Das, S. I. Khondaker and S. Seal, Graphene based materials: Past; present and future, Prog. Mater. Sci., 2011, 56(8), 1178-1271.

23 N. Saleh, H. J. Kim, T. Phenrat, K. Matyjaszewski, R. D. Tilton and G. V. Lowry, Ionic Strength and Composition Affect the Mobility of Surface-Modified $\mathrm{Fe}^{0}$ Nanoparticles in WaterSaturated Sand Columns, Environ. Sci. Technol., 2008, 42(9), 3349-3355.

$24 \mathrm{~F}$. Yu, S. Sun, J. Ma and S. Han, Enhanced removal performance of arsenate and arsenite by magnetic graphene oxide with high iron oxide loading, Phys. Chem. Chem. Phys., 2015, 17, 4388-4397.

25 D. Dinda, A. Gupta and S. K. Saha, Removal of toxic Cr(vi) by UV active functionalized graphene oxide for water purification, J. Mater Chem. A, 2013, 1(37), 11221-11228.

26 A. S. K. Kumar and N. Rajesh, Exploring the interesting interaction between graphene oxide; Aliquat-336 (a room temperature ionic liquid) and chromium(vi) for wastewater treatment, RSC Adv., 2013, 3(8), 2697-2709.

27 Y. Gao, Y. Li, L. Zhang, H. Huang, J. Hu, S. M. Shah and $\mathrm{X}$. Su, Adsorption and removal of tetracycline antibiotics from aqueous solution by graphene oxide, $J$. Colloid Interface Sci., 2012, 368, 540-546.

28 V. Chandra and K. S. Kim, Highly selective adsorption of $\mathrm{Hg}^{2+}$ by a polypyrrole-reduced graphene oxide composite, Chem. Commun., 2011, 47, 3942-3944.

29 W. Gao, M. Majumder, L. B. Alemany, T. N. Narayanan, M. A. Ibarra, B. K. Pradhan and P. M. Ajayan, Engineered Graphite Oxide Materials for Application in Water Purification, ACS Appl. Mater. Interfaces, 2011, 3, 1821-1826.

30 V. Chandra, J. Park, Y. Chun, J. W. Lee, I. C. Hwang and K. S. Kim, Water-Dispersible Magnetite-Reduced Graphene Oxide Composites for Arsenic Removal, ACS Nano, 2010, 4(7), 3979-3986.

31 T. S. Sreeprasad, S. S. Gupta, S. M. Maliyekkal and T. Pradeep, Immobilized graphene-based composite from asphalt: Facile synthesis and application in water purification, J. Hazard. Mater., 2013, 246-247, 213-220.

32 K. Zhang, V. Dwivedi, C. Chi and J. Wu, Graphene oxide/ ferric hydroxide composites for efficient arsenate removal from drinking water, J. Hazard. Mater., 2010, 182, 162-168.

33 Z. Ding, X. Hu, V. L. Morales and B. Gao, Filtration and transport of heavy metals in graphene oxide enabled sand columns, Chem. Eng. J., 2014, 257, 248-252.
34 A. Y. Romanchuk, A. S. Slesarev, S. N. Kalmykov, D. V. Kosynkinz and J. M. Tour, Graphene oxide for effective radionuclide removal, Phys. Chem. Chem. Phys, 2013, 15, 2321-2327.

35 S. T. Yang, S. Chen, Y. Chang, A. Cao, Y. Liu and H. Wang, Removal of methylene blue from aqueous solution by graphene oxide, J. Colloid Interface Sci., 2011, 359, 24-29.

36 C. Wang, J. Ni, J. Zhou, J. Wen and X. Lü, Strategically designed porous polysilicate acid/graphene composites with wide pore size for methylene blue removal, RSC Adv., 2013, 3, 23139-23145.

37 L. Cui, Y. Wang, L. Hu, L. Gao, B. Du and Q. Wei, Mechanism of $\mathrm{Pb}$ (II) and methylene blue adsorption onto magnetic carbonate hydroxyapatite/grapheme oxide, RSC Adv., 2015, 5, 9759-9770.

38 S. Song, Y. Ma, H. Shen, M. Zhang and Z. Zhang, Removal and recycling of ppm levels of methylene blue from an aqueous solution with grapheme oxide, $R S C A d v$., 2015, 5, 27922-27932.

39 Y. Guo, J. Deng, J. Zhu, C. Zhou, C. Zhou, X. Zhou and R. Bai, Removal of anionic azo dye from water with activated graphene oxide: kinetic, equilibrium and thermodynamic modeling, RSC Adv., 2016, 6, 39762-39773.

40 A. Asfaram, M. Ghaedi, A. Goudarzi and M. Rajabi, Response surface methodology approach for optimization of simultaneous dyes and metal ions ultrasound-assisted adsorption onto $\mathrm{Mn}$ doped $\mathrm{Fe}_{3} \mathrm{O}_{4}$-NPs loaded on $\mathrm{AC}$ : Kinetic and isotherm study, Dalton Trans., 2015, 44, 1470714723.

41 W. S. Hummers and R. E. Offeman, J. Am. Chem. Soc., 1958, 80, 1339.

42 D. C. Marcano, D. V. Kosynkin, J. M. Berlin, A. Sinitskii, Z. Sun, A. Slesarev, L. B. Alemany, W. Lu and J. M. Tour, Improved Synthesis of Graphene Oxide, ACS Nano, 2010, 4(8), 4806-4814.

43 S. Stankovich, D. A. Dikin, G. H. B. Dommett, K. M. Kohlhaas, E. J. Zimney, E. A. Stach, R. D. Piner, S. T. Nguyen and R. S. Ruoff, Graphene-based composite materials, Nature, 2006, 442, 282-286.

44 S. Stankovich, D. A. Dikin, R. D. Piner, K. A. Kohlhaas, A. Kleinhammes, Y. Jia, Y. Wu, S. T. Nguyen and R. S. Ruoff, Synthesis of graphene-based nanosheets via chemical reduction of exfoliated graphite oxide, Carbon, 2007, 45, 1558-1565.

45 S. Park, J. An, I. Jung, R. D. Piner, S. J. An, X. Li, A. Velamakanni and R. S. Ruoff, Colloidal Suspensions of Highly Reduced Graphene Oxide in a Wide Variety of Organic Solvents, Nano Lett., 2009, 9(4), 1593-1597.

46 S. Park, J. An, J. R. Potts, A. Velamakanni, S. Murali and R. S. Ruoff, Hydrazine-reduction of graphite- and graphene oxide, Carbon, 2011, 49, 3019-3023.

47 I. Chowdhury, M. C. Duch, N. D. Mansukhani, M. C. Hersam and D. Bouchard, Colloidal Properties and Stability of Graphene Oxide Nanomaterials in the Aquatic Environment, Environ. Sci. Technol., 2013, 47(12), 6288-6296.

48 S. G. Wang, X. W. Liu, W. X. Gong, W. Nie, B. Y. Gao and Q. Y. Yue, Adsorption of fulvic acids from aqueous 
solutions by carbon nanotubes, J. Chem. Technol. Biotechnol., 2007, 82, 698-704.

49 S. G. Wang, X. F. Sun, X. W. Liu, W. X. Gong, B. Y. Gao and N. Bao, Chitosan hydrogel beads for fulvic acid adsorption: Behaviors and mechanisms, Chem. Eng. J., 2008, 142, 239247.

50 T. Mohanta and S. Goel, Assessment of Water Quality of Three Different Aquatic Environments Over Three Seasons, Singapore 1st International Congress on Environmental, Biotechnology, and Chemistry Engineering. IPCBEE, IACSIT Press, 2014, p. 64.

$51 \mathrm{H}$. Fu and X. Quan, Complexes of fulvic acid on the surface of hematite, goethite, and akaganeite: FTIR observation, Chemosphere, 2006, 63(3), 403-410.

52 E. Y. Choi, T. H. Han, J. Hong, J. E. Kim, S. H. Lee, H. W. Kim and S. O. Kim, Noncolvalent functionalization of Graphene with end-functional Polymers, J. Mater. Chem., 2010, 20, 1907-1912.

53 F. Y. Ban, S. R. Majid, N. M. Huang and H. N. Lim, Graphene oxide and its electrochemical performance, Int. J. Electrochem. Sci., 2012, 7, 4345-4351.

54 Z. C. Ling and A. Wang, A systematic spectroscopic study of eight hydrous ferric sulfates relevant to Mars, Icarus, 2010, 209(2), 422-433.

55 D. R. Dreyer, S. Park, C. W. Bielawski and R. S. Ruoff, The chemistry of graphene oxide, Chem. Soc. Rev., 2010, 39, 228-240.

56 R. K. Upadhyay, N. Soin and S. S. Roy, Role of graphene/ metal oxide composites as photocatalysts; adsorbents and disinfectants in water treatment: a review, $R S C A d v ., 2014$, 4, 823-3851.

57 L. Jiang, Y. Liu, G. Zeng, F. Xiao, X. Hua, X. Hu, H. Wang, T. Li, L. Zhou and X. Tan, Removal of $17 \mathrm{~b}$-estradiol by fewlayered graphene oxide nano sheets from aqueous solutions: External influence and adsorption mechanism, Chem. Eng. J., 2016, 284, 93-102.

58 T. S. Sreeprasad, S. M. Maliyekkal, K. P. Lisha and T. Pradeep, Reduced graphene oxide-metal/metal oxide composites: Facile synthesis and application in water purification, J. Hazard. Mater., 2011, 186(1), 921-931.

59 P. K. Boruah, D. J. Borah, J. Handique, P. Sharma, P. Sengupta and M. R. Das, Facile synthesis and characterization of $\mathrm{Fe}_{3} \mathrm{O}_{4}$ nanopowder and $\mathrm{Fe}_{3} \mathrm{O}_{4}$ /reduced graphene oxide nanocomposite for methyl blue adsorption: A comparative study, J. Environ. Chem. Eng., 2015, 3(3), 1974-1985.

60 X. Sheng, W. Cai, L. Zhong, D. Xie and X. Zhang, Synthesis of Functionalized Graphene/Polyaniline Nanocomposites with Effective Synergistic Reinforcement on Anticorrosion, Ind. Eng. Chem. Res., 2016, 55, 8576-8585.

61 J. R. Lead, E. Balnois, M. Hosse, R. Menghetti and K. J. Wilkinson, Characterization of Norwegian natural organic matter: size, diffusion coefficients and electrophoretic mobilities, Environ. Int., 1999, 25(2/3), 245258.

$62 \mathrm{~J}$. Guo and J. Ma, AFM study on the sorbed NOM and its fractions isolated from River Songhua, Water Res., 2006, 40, 1975-1984.

63 X. Fang, X. Xu, S. Wang and D. Wang, Adsorption Kinetics and Equilibrium of $\mathrm{Cu}(\mathrm{II})$ from Aqueous Solution by Polyaniline/Coconut Shell-Activated Carbon Composites, $J$. Environ. Eng., 2013, 139, 1279-1284.

64 F. C. Wu, R. L. Tseng and R. S. Juang, Characteristics of Elovich equation used for the analysis of adsorption kinetics in dye-chitosan systems, Chem. Eng. J., 2009, 150, 366-373.

65 Q. Zhou, Y. H. Zhong, X. Chen, J. H. Liu, X. J. Huang and Y. C. Wu, Adsorption and photocatalysis removal of fulvic acid by $\mathrm{TiO}_{2}$-graphene composites, J. Mater. Sci., 2014, 49, 1066-1075.

66 S. Vreysen and A. Maes, Adsorption mechanism of humic and fulvic acid onto $\mathrm{Mg} / \mathrm{Al}$ layered double hydroxides, Appl. Clay Sci., 2008, 38, 237-249.

67 Y. S. Ho and G. McKay, Pseudo-second order model for sorption processes, Process Biochem., 1999, 34, 451-465.

$68 \mathrm{~K}$. V. Kumar, Linear and non-linear regression analysis for the sorption kinetics of methylene blue onto activated carbon, J. Hazard. Mater., 2006, B137, 1538-1544.

69 W. Stumm, L. Sigg and B. Sulzberger. Chemistry of the SolidWater Interface: Processes at the Mineral-Water and ParticleWater Interface in Natural Systems, Wiley, 1992, p. 112.

70 A. A. M. Daifullah, B. S. Girgis and H. M. H. Gad, A study of the factors affecting the removal of humic acid by activated carbon prepared from biomass material, Colloids Surf., A, 2004, 235(1-3), 1-10.

71 S. Pourbeyram, Effective Removal of Heavy Metals from Aqueous Solutions by Graphene Oxide-Zirconium Phosphate (GO-Zr-P) Nanocomposite, Ind. Eng. Chem. Res., 2016, 55, 5608-5617. 